\title{
Micro-fine finishing of a feldspar porcelain for dental prostheses
}

\author{
Xiao-Fei Song ${ }^{a}$, Ling Yin ${ }^{\mathrm{b}, *}$, Yi-Gang Han ${ }^{\mathrm{a}}$, Hui Wang ${ }^{\mathrm{c}}$ \\ a School of Mechanical Engineering, Tianjin University, Tianjin 300072, China \\ ${ }^{\mathrm{b}}$ Department of Engineering, Building 32, Australian National University, ACT 0200, Australia \\ ${ }^{\mathrm{c}}$ Analysis \& Measurement Center, Tianjin University, Tianjin 300072, China
}

Received 20 June 2007; received in revised form 10 September 2007; accepted 16 October 2007

\begin{abstract}
Intraoral adjustment of ceramic prostheses involving micro-finishing using diamond burs is a critical procedure in restorative dentistry because the durability of a restoration depends on the finishing process and quality. Force, energy and surface integrity in micro-fine finishing of a feldspar porcelain versus operational parameters were investigated using a 2-DOF (two-degrees-of-freedom) high-speed dental handpiece and a fine diamond bur of 20-30 $\mathrm{m}$ grits. The tangential and normal forces were measured as being significantly small in the ranges $0.18-0.35 \mathrm{~N}$ and $0.22-0.59 \mathrm{~N}$, respectively. High specific finishing energy of $110-2523 \mathrm{~J} / \mathrm{mm}^{3}$ was observed in material removal, particularly when decreasing either the depth of cut or the feed rate. Scanning electron microscopy observations indicated that the surfaces generated were mainly due to ductile flow; however, microfractures also occurred in porcelain. Surface roughness was measured as $0.43-0.74 \mu \mathrm{m}$ in terms of arithmetic mean value $\left(R_{\mathrm{a}}\right)$, decreasing with the depth of cut, but insignificantly changing with the feed rate (ANOVA, $P>0.05$ ). Recommendations for clinical practice are made on the basis of our testing results.
\end{abstract}

(C) 2007 IPEM. Published by Elsevier Ltd. All rights reserved.

Keywords: Micro-fine finishing; Feldspar porcelain; Surface morphology; Finishing force; Finishing energy

\section{Introduction}

Feldspar porcelains have been attractive materials in restorative dentistry because of their approximations to the appearances and functions of human enamels [1-6]. A machinable feldspar porcelain is one of the ceramic materials for dental CAD/CAM [7-9]. However, this porcelain is brittle in nature and susceptible to machining-induced damage $[2,3,10-12]$.

Studies have shown that the feldspar porcelains suffer from extensive chipping defects and microcracks in dental CAD/CAM processes, due to their high amount of glassy phase $[2,13,14]$. Also, in intraoral dental finishing of the porcelain using dental handpieces and burs, extensive chipping damage and subsurface damage were introduced in the feldspar porcelain when using coarse grit diamond burs [15-17]. Analyses of failed crowns have proven that catas-

\footnotetext{
* Corresponding author. Tel.: +6126125 8536; fax: +61 261250506

E-mail address: ling.yin@anu.edu.au (L. Yin).
}

trophic fracture had always originated from surface and subsurface damage in ceramic prostheses [10], which results in a reduction in strength and lifetime of the restorations $[2,8,18-20]$. Furthermore, wear studies show that the surface roughness of the ceramic prostheses greatly influence enamel wear [21]. Therefore, the diminution of finishinginduced damage for good surface quality becomes a major task in restorative dentistry.

Although high-speed dental handpieces/burs have been routinely used in dentistry for over 30 years [22,23], little work has been reported on their performance in dental operations, particularly concerning the amount of damage introduced in ceramic prostheses depending on the dental burs [8]. There is a practical interest in the characterization of the performance of diamond burs in intraoral resurfacing of dental bioceramics in restorative dentistry [8]. Some studies have found that fine grit diamond burs can be applied for improvement of surface roughness and reduction of subsurface damage $[15,24,25]$. Although these studies provided insights in grit size effect on dental restorations, they also 
ignored the dynamic and variable aspects in clinical processes because they were conducted at fixed loads under static conditions $[15,24,25]$, which entirely differ from changeable dental operations. Recent studies on in vitro dental finishing using coarse burs have found that the forces and handpiece speeds depended on the operational parameters $[17,26]$. However, the influence of operational parameters on micro-fine finishing process and quality using fine burs remains unknown, even though it is critical to dental restorations.

In this paper we describe the in vitro micro-fine finishing of a feldspar porcelain using a 2-DOF high-speed dental handpiece and fine diamond grits under a wide range of conditions. Finishing force, energy, speed, surface roughness, and surface morphology were investigated as a function of the relevant dental operational parameters. Implications concerning the intraoral adjustment using fine diamond grits in dental practice are considered.

\section{Experimental procedure}

\subsection{Dental material}

The specimens were feldspar porcelain blocks of $15 \mathrm{~mm} \times 12 \mathrm{~mm} \times 5 \mathrm{~mm}$ in dimension, Vita Mark II (Vita Zahnfabrik, Germany). Their microstructure comprises a glass matrix and approximately $30 \%$ irregular feldspar crystals of sanidine, nepheline and anothoclase [17] of 1-7 $\mu \mathrm{m}$ in size [27]. Their mechanical properties are: Vickers hardness $H=6.2 \mathrm{GPa}$, Young's modulus $E=68 \mathrm{GPa}$, fracture toughness $K_{\mathrm{c}}=0.9 \mathrm{MPa} \mathrm{m}^{1 / 2}$, and strength $\sigma=100 \mathrm{MPa}$ [28].

\subsection{Micro-fine finishing}

Micro-fine finishing was conducted on a 2-DOF computer-assisted apparatus. A detailed description of the apparatus was given in a previous study [26]. This apparatus included a computer-controlled $x-y$ table (TKQ8163P/50*50, Zhonghuan, China), a high-speed dental handpiece (PA-S, NSK, Japan), a piezoelectric force dynamometer (9257 A, Kistler, Switzerland), a charge amplifier (5006, Kistler, Switzerland) and a data acquisition system (LMS SCADAS III 305, LMS International, Belgium).

A new diamond bur of diameter of $d_{\mathrm{s}}=1.3 \mathrm{~mm}$ and grits of 20-30 $\mu \mathrm{m}$ (SF114, ISO 158/013, Shofu, Japan) was used. The bur against the specimen in micro-finishing is illustrated in Fig. 1 . The bur, rotating with peripheral speed $v_{\mathrm{s}}$, was moved in the long direction of the $12 \mathrm{~mm} \times 5 \mathrm{~mm}$ surface at a feed rate $v_{\mathrm{w}}$ and a depth of cut $a$. The handpiece was driven at air pressure $0.17 \mathrm{MPa}$ at the rotational speed of $357.3 \mathrm{krpm}$ when unloaded. Water was delivered to the finishing area at a constant flow rate of $30 \mathrm{ml} / \mathrm{min}$. The finishing tests were conducted at feed rates of $12-36 \mathrm{~mm} / \mathrm{min}$ and depths of cut of 2-20 $\mu \mathrm{m}$. The micro-fine finishing conditions are summarized in Table 1.

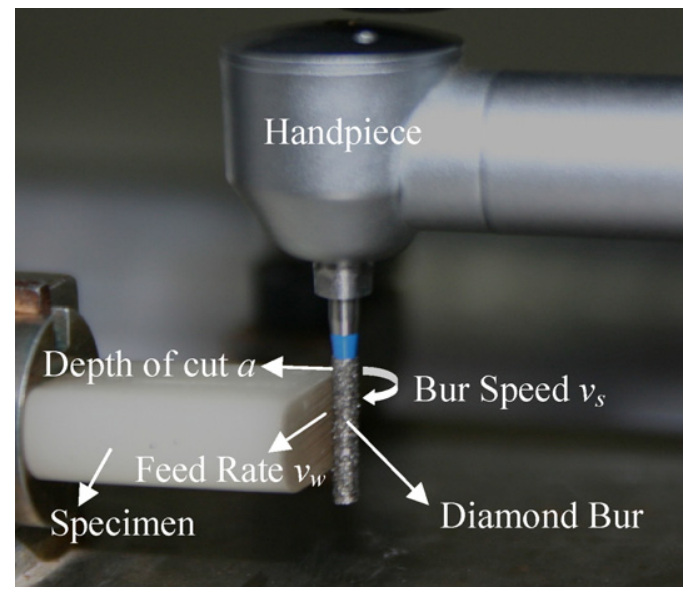

Fig. 1. Dental handpiece, bur, and specimen in finishing.

\subsection{Characterization methodology}

Tangential and normal forces were measured using a dynamometer, a charge amplifier, and a data acquisition system. The normal force is in the depth of cut direction and the tangential force is in the feed direction. The bur speed was obtained from the frequencies corresponding to the largest amplitudes of the tangential and normal force data in the frequency domain using a fast Fourier transform [26].

The specific finishing energy $u$ is defined as the energy expended per unit volume of material removed and calculated as [29]:

$u=\frac{F_{\mathrm{t}} v_{\mathrm{s}}}{a v_{\mathrm{w}} b}$

where $F_{\mathrm{t}}$ is the tangential force, $v_{\mathrm{s}}$ is the bur speed, $a$ is the depth of cut, $v_{\mathrm{w}}$ is the feed rate, and $b$ is the specimen thickness. $F_{\mathrm{t}} v_{\mathrm{s}}$ is the finishing power and $a v_{\mathrm{w}} b$ is the volume of material removed per unit time.

The arithmetic mean surface roughness $\left(R_{\mathrm{a}}\right)$ was measured using a stylus profilometer (Taylor Hobson, UK). Surface morphology was examined by scanning electron microscopy (SEM, XL-30, Philips, Holland). For force and roughness testing, three separate measurements were made under each finishing condition to obtain mean values and

Table 1

Micro-fine finishing conditions

\begin{tabular}{ll}
\hline Parameter & Value \\
\hline Dental handpiece & NSK PA-S, high speed air-turbine dental handpiece \\
Dental bur & SF114, ISO 158/013, fine diamond grits of 20-30 $\mu \mathrm{m}$ \\
Dental material & $\begin{array}{l}\text { Vita Mark II V5-12 A1C, fine-particle feldspar } \\
\text { porcelain }\end{array}$ \\
Air pressure & $0.17 \mathrm{MPa}$ \\
Water flow rate & $30 \mathrm{ml} / \mathrm{min}$ \\
Depth of cut & $2 \mu \mathrm{m}, 5 \mu \mathrm{m}, 10 \mu \mathrm{m}, 15 \mu \mathrm{m}$, and $20 \mu \mathrm{m}$ \\
Feed rate & $12 \mathrm{~mm} / \mathrm{min}, 18 \mathrm{~mm} / \mathrm{min}, 24 \mathrm{~mm} / \mathrm{min}, 30 \mathrm{~mm} / \mathrm{min}$, \\
& and $36 \mathrm{~mm} / \mathrm{min}$
\end{tabular}


standard deviations. A two-way factorial analysis of variance (ANOVA) at a 5\% significance level was applied for statistical analyses.

\section{Results}

\subsection{Finishing forces and force ratios}

The tangential force $F_{\mathrm{t}}$ as a function of feed rate for different depths of cut is summarized in Fig. 2(a). It shows that tangential forces were small and in the range $0.18-0.35 \mathrm{~N}$. At the depths of cut of $2 \mu \mathrm{m}$ and $10 \mu \mathrm{m}$ they remained relatively steady with the feed rate; at the depth of cut of $20 \mu \mathrm{m}$ they increased slightly with the feed rate. At the feed rate of $12 \mathrm{~mm} / \mathrm{min}$, the change in tangential forces was not significant $(P>0.05)$ as a function of depth of cut.

The tangential force $F_{\mathrm{t}}$ as a function of depth of cut for different feed rates is plotted in Fig. 2(b). At the feed rate of $12 \mathrm{~mm} / \mathrm{min}$, the tangential force increased significantly when the depth of cut increased from $2 \mu \mathrm{m}$ to $15 \mu \mathrm{m}$, but sharply decreased when the depth of cut was $20 \mu \mathrm{m}$. At the feed rate of $24 \mathrm{~mm} / \mathrm{min}$ the force increased by about $53 \%$ from $0.22 \mathrm{~N}$
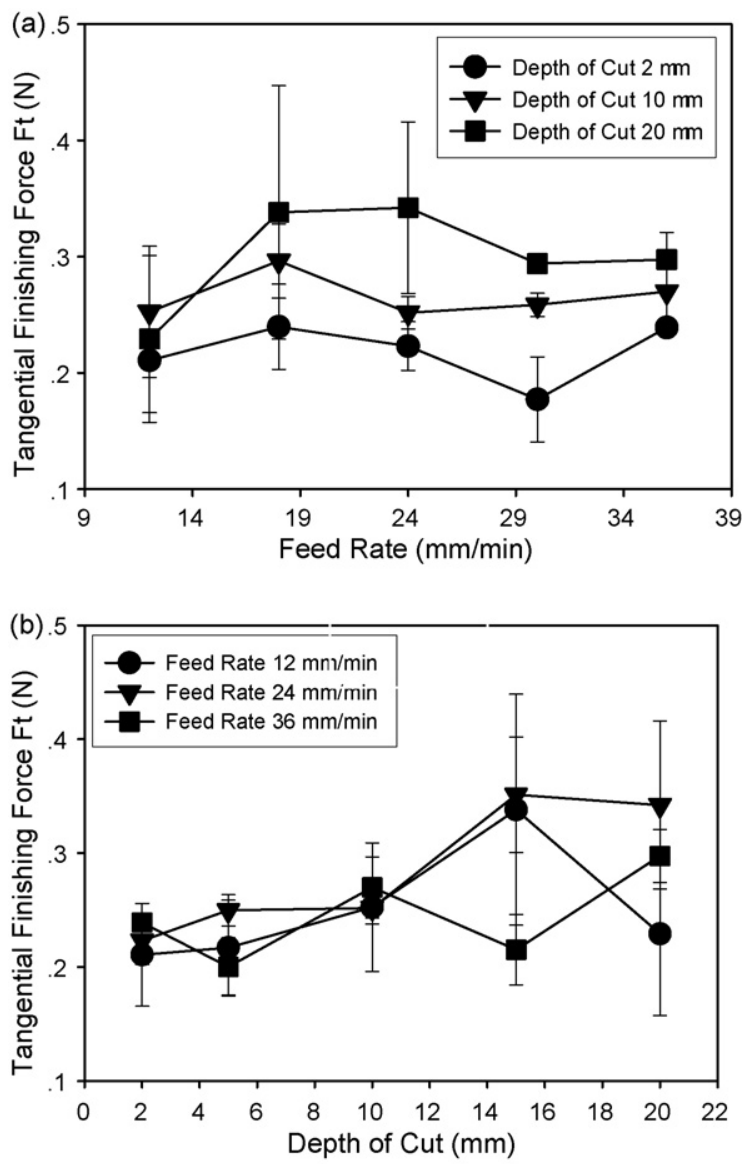

Fig. 2. (a) Tangential force $F_{\mathrm{t}}$ vs. feed rate; (b) tangential force $F_{\mathrm{t}}$ vs. depth of cut.
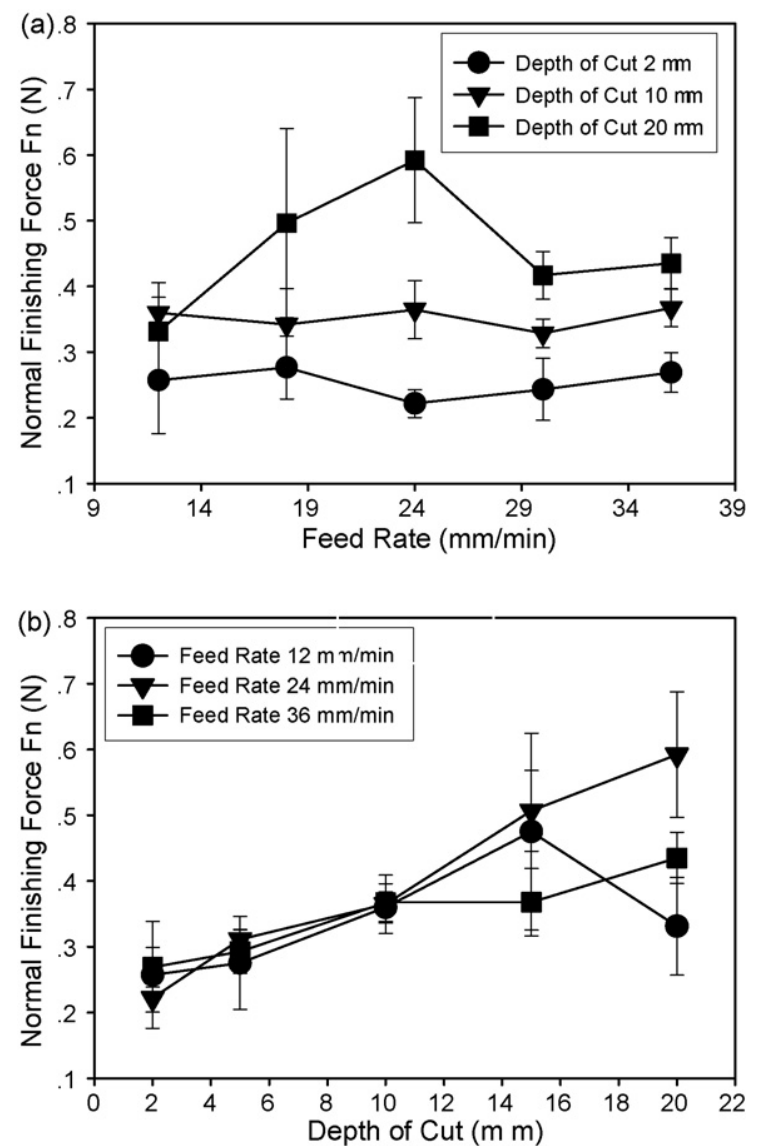

Fig. 3. (a) Normal force $F_{\mathrm{n}}$ vs. feed rate; (b) normal force $F_{\mathrm{n}}$ vs. depth of cut.

to $0.34 \mathrm{~N}$ with the depth of cut. At the feed rate of $36 \mathrm{~mm} / \mathrm{min}$ the force increased by about $25 \%$ from $0.24 \mathrm{~N}$ to $0.30 \mathrm{~N}$. At the depths of cut smaller than $10 \mu \mathrm{m}$, the influence of the feed rate on tangential force was not significant $(P>0.05)$.

The normal force $F_{\mathrm{n}}$ as a function of feed rate for different depths of cut is given in Fig. 3(a). It indicates that normal forces were in the ranges $0.22-0.28 \mathrm{~N}$ and $0.33-0.37 \mathrm{~N}$ for the different feed rates at the depths of cut $2 \mu \mathrm{m}$ and $10 \mu \mathrm{m}$, respectively. At the depth of cut of $20 \mu \mathrm{m}$, the forces were $0.41-0.59 \mathrm{~N}$ for the feed rates of $18-36 \mathrm{~mm} / \mathrm{min}$.

The normal force $F_{\mathrm{n}}$ as a function of depth of cut for different feed rates is shown in Fig. 3(b). It shows that normal forces increased with an increase in depth of cut for all feed rates, except for an abrupt decrease at the feed rate of $12 \mathrm{~mm} / \mathrm{min}$ when the depth of cut was $20 \mu \mathrm{m}$. The effect of the feed rate on the normal force was not significant $(P>0.05)$, especially at the depths of cut smaller than $10 \mu \mathrm{m}$.

The force ratio $F_{\mathrm{n}} / F_{\mathrm{t}}$ as a function of feed rate for different depths of cut is given in Fig. 4(a), scaling to 1.0-1.7 for the depths of cut of $2-20 \mu \mathrm{m}$. The effect of the feed rate on the force ratio was not significant $(P>0.05)$.

The force ratio as a function of depth of cut for different feed rates is shown in Fig. 4(b). It increased with the 

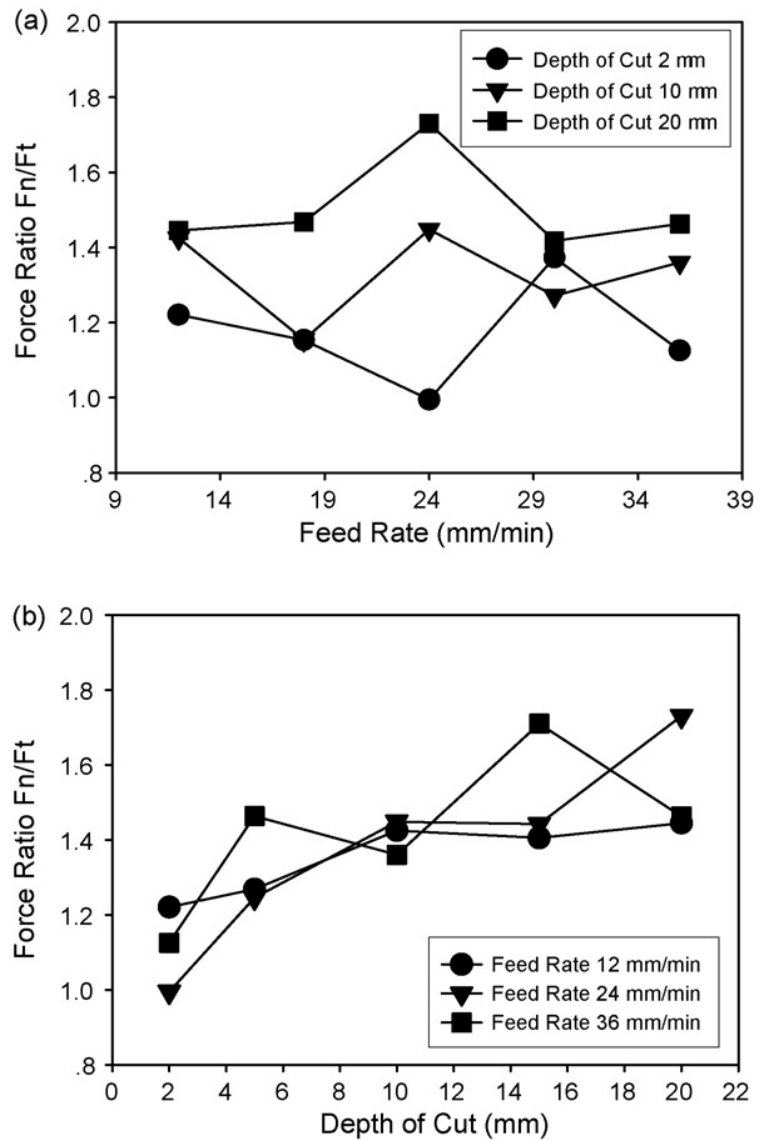

Fig. 4. (a) Force ratio $F_{\mathrm{n}} / F_{\mathrm{t}}$ vs. feed rate; (b) force ratio $F_{\mathrm{n}} / F_{\mathrm{t}}$ vs. depth of cut.

depth of cut, by $19 \%, 74 \%$, and $30 \%$ for the feed rates of $12 \mathrm{~mm} / \mathrm{min}, 24 \mathrm{~mm} / \mathrm{min}$, and $36 \mathrm{~mm} / \mathrm{min}$, respectively, in the range $1.0-1.7$.

\subsection{Bur rotational speed and specific finishing energy}

The rotational speed of the bur as a function of feed rate for different depths of cut is plotted in Fig. 5(a). The speeds decreased with the feed rate at any depth of cut. Bur rotational speed as a function of depth of cut for different feed rates is plotted in Fig. 5(b). The speeds decreased with the depth of cut at any feed rate.

The specific finishing energy as a function of feed rate for different depths of cut is given in Fig. 6(a). The energy decreased with the feed rate at any depth of cut. At the depth of cut of $2 \mu \mathrm{m}$, the energy dropped remarkably by $62 \%$ from $2523 \mathrm{~J} / \mathrm{mm}^{3}$ to $959 \mathrm{~J} / \mathrm{mm}^{3}$. It is also noticeable that specific energy values at the depth of cut of $2 \mu \mathrm{m}$ were $3-4$ and 5-8 times larger than those at the depths of cut $10 \mu \mathrm{m}$ and $20 \mu \mathrm{m}$, respectively.

The specific finishing energy as a function of depth of cut for different feed rates is plotted in Fig. 6(b). The energy significantly decreased with the depth of cut at any feed rate.
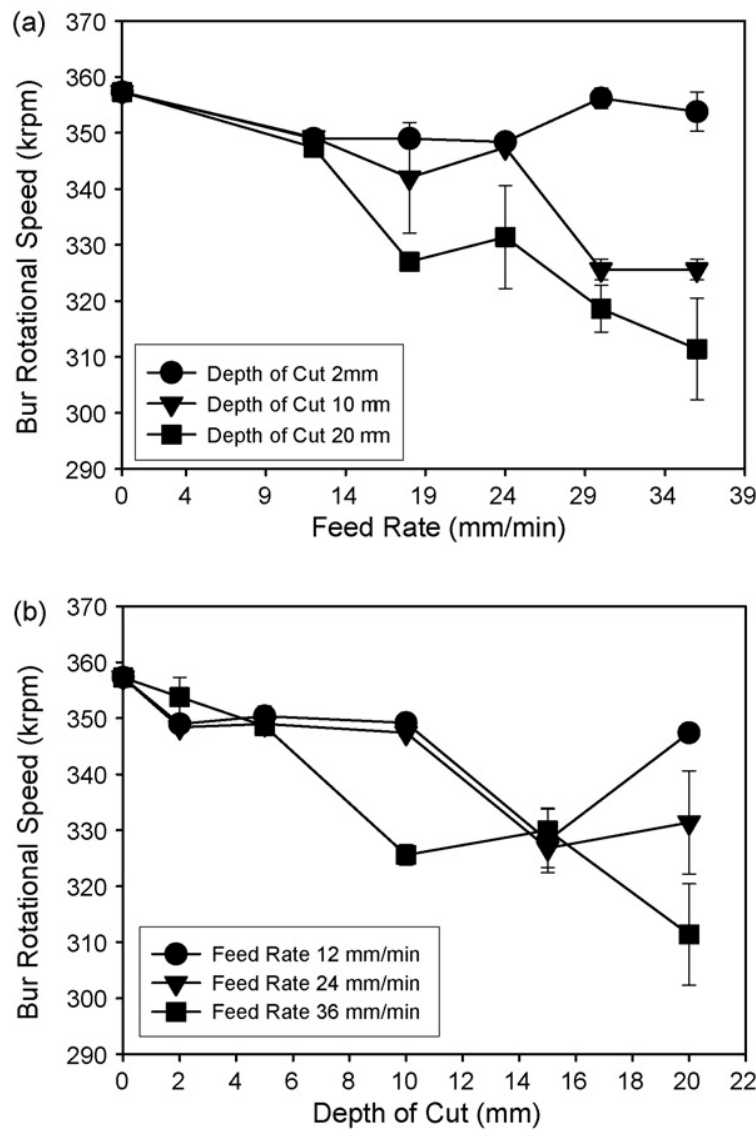

Fig. 5. (a) Bur rotational speed vs. feed rate; (b) bur rotational speed vs. depth of cut.

At the lower feed rates, the energy values were higher than those at the higher feed rates at any depth of cut. Moreover, the energy decreased at more rapid rates when the depths of cut increased from $2 \mu \mathrm{m}$ to $10 \mu \mathrm{m}$ than from $10 \mu \mathrm{m}$ to $20 \mu \mathrm{m}$.

\subsection{Surface roughness and morphology}

Arithmetic mean roughness $R_{\mathrm{a}}$ as a function of feed rate at depths of cut of $2 \mu \mathrm{m}$ and $20 \mu \mathrm{m}$ are summarized in Fig. 7 . At the depth of cut of $2 \mu \mathrm{m}, R_{\mathrm{a}}$ values were smaller than those at the depth of cut of $20 \mu \mathrm{m}$, in the range $0.43-0.54 \mu \mathrm{m}$ and $0.55-0.74 \mu \mathrm{m}$ for the depths of cut $2 \mu \mathrm{m}$ and $20 \mu \mathrm{m}$, respectively. The effect of the feed rate on $R_{\mathrm{a}}$ was insignificant $(P>0.05)$.

SEM micrographs of the finished surfaces at the depths of cut $2 \mu \mathrm{m}$ and $20 \mu \mathrm{m}$ for the complete variation of feed rates of $12-36 \mathrm{~mm} / \mathrm{min}$ are shown in Figs. 8 and 9, respectively. The surfaces generated under the selected finishing conditions are similar, with large smooth areas and plough striations by ductile cutting. Microfractures were also observed on the surfaces. Fig. 8 shows an increasing tendency to microfracture with increasing feed rate. At lower feed rates, typical plastic flow, similar to those in ductile removal, was observed; small fragmentations due to microfracture also occurred on 

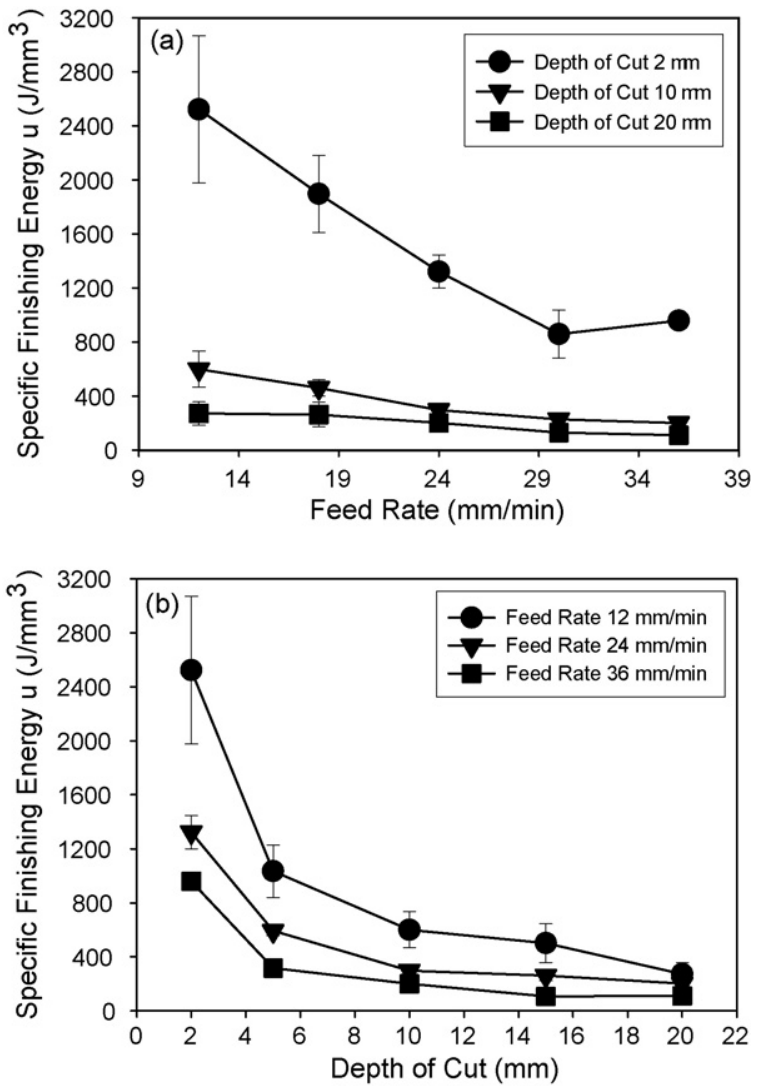

Fig. 6. (a) Specific energy $u$ vs. feed rate; (b) specific energy $u$ vs. depth of cut.

the flanks of the plastic flow, as shown in Fig. 8(a and b). At higher feed rates, more microfracture areas were visible, as shown in Fig. 8(c-e). In comparison with Fig. 8, Fig. 9 shows that there is more microfracture occurring at the depth of cut $20 \mu \mathrm{m}$, especially at higher feed rates where more chipping damage and cleavage fracture were observed, as shown in Fig. 9(d and e).

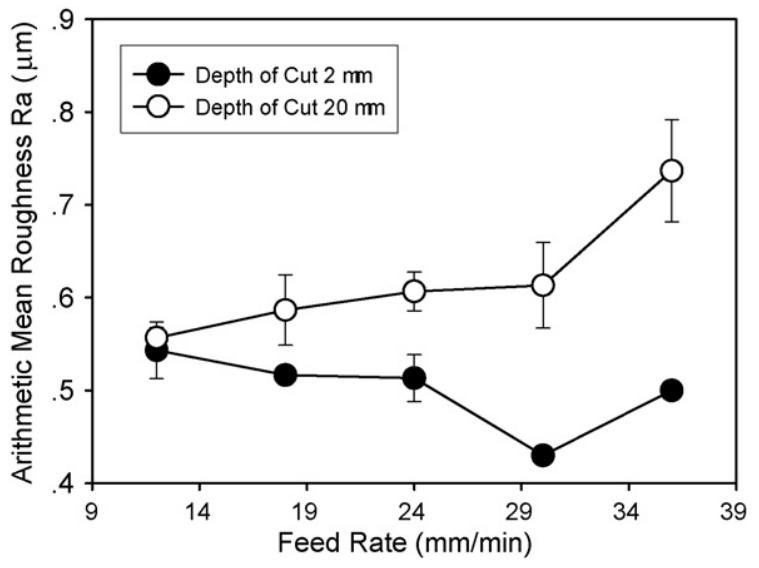

Fig. 7. Arithmetic mean roughness $R_{\mathrm{a}}$ vs. feed rate.

\section{Discussion}

In clinical restorations, ceramic prostheses are resurfaced by fast-rotating multiple diamond grits at a particular feed rate and depth of cut or infeed. The forces generated between the diamond bur and the ceramic prostheses are related to the resurfacing parameter as well as to the material properties [30]. The overall resurfacing force is composed of forces acting on individual diamond grits as they indent and scratch the ceramic prosthesis to remove material from the surface by a combination of chip-formation, fatigue and fracture processes. The details of the removal process are determined by the nature of the abrasive particles (shape, strength, size, etc.), the properties of the ceramic prostheses (hardness, elastic modulus, fracture toughness, etc.), the magnitude of the interaction forces between the abrasive grits and the ceramic prosthesis, the time-dependence of the forces, the nature of surrounding environment (coolant and chips). In particular, force-related physics involving in dental resurfacing becomes more significant.

Tangential and normal forces showed upward trends relative to depth of cut. This is consistent with common findings in conventional machining [31]. However, similar upward trends relative to the feed rate were not clearly evident. The force ratio $F_{\mathrm{n}} / F_{\mathrm{t}}$ is associated with the coefficient of friction, and varied in the range 1-1.25 in the dental removal of enamel [32]. The obtained force ratios of 1-1.7 for porcelain, were close to those for enamel. But they were much lower than those for the same porcelain when finishing with coarse diamond grits, where the force ratio values were 3-5 [17]. This indicates that more friction occurred in dental finishing processes using fine diamond grits than in finishing using coarse grits. This may be attributed to more ductile flow involved in the removal process, which resulted in more friction between the diamond grits and the porcelain material.

Specific energy is a direct consequence of the removal mechanisms [33]. At smaller depths of cut or feed rates, corresponding to lower removal rates and smaller grit depths of cut, the specific energy was large, as shown in Fig. 6 . Since specific energy is mainly expended by ductile flow (plowing) [34,35], the steep increase of specific energy at very small depths of cut can be attributed to an increased tendency for ductile flow. Surface roughness decreases when the ductile cutting mechanism prevails in material removal [36]. Therefore, a better surface finish might correspond to a larger specific energy due to more energy being expended by plastic deformation. The results of surface roughness also show this consistent trend in the current study. The smaller depth of cut, corresponding to larger specific energy, resulted in a better surface finish, as shown in Fig. 7. However, these specific energies in dental micro-fine finishing are significantly higher than those in conventional machining of ceramics or glasses where the specific energies normally ranged from $10 \mathrm{~J} / \mathrm{mm}^{3}$ to $800 \mathrm{~J} / \mathrm{mm}^{3}$ [35,37]. In spite of the better surface finish generated at the low depth of cut, high specific energies are partially released in the form of heat $[29,32]$. Thus, the high 
(a)

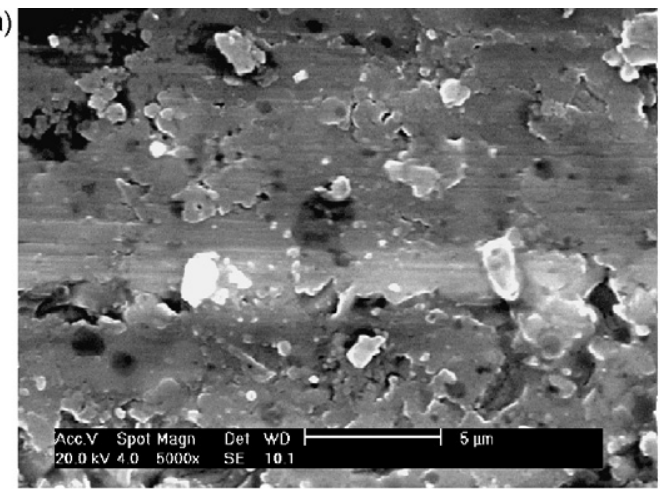

(c)

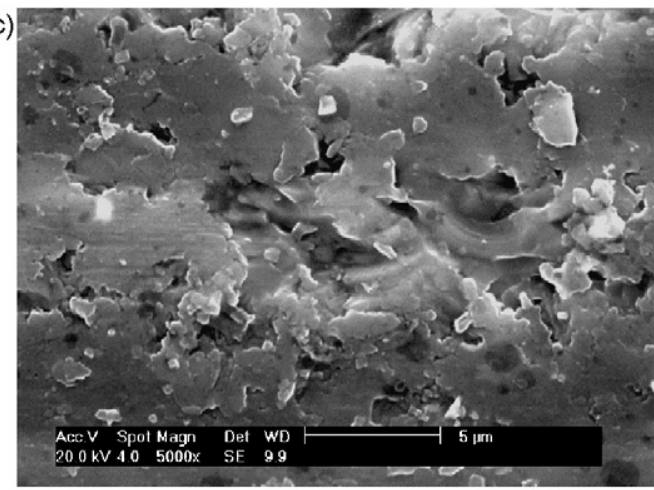

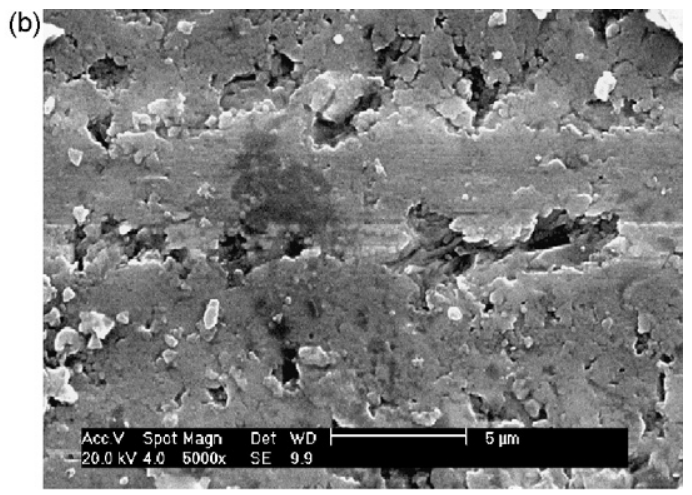

(d)

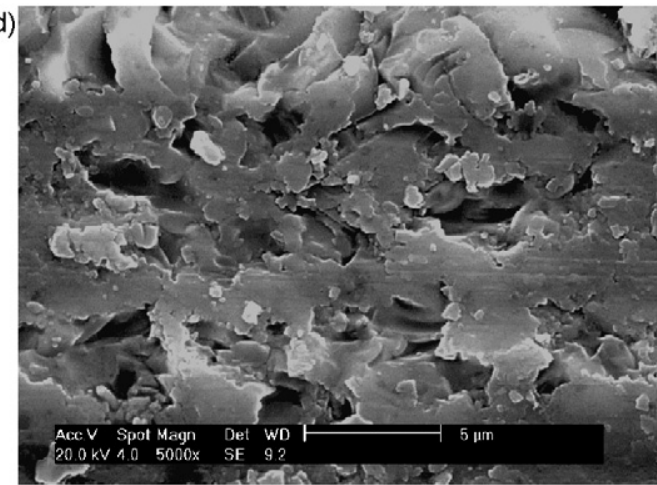

(e)

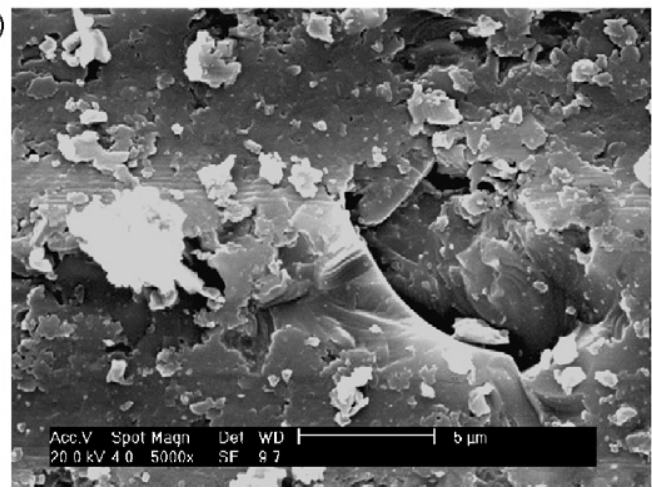

Fig. 8. SEM micrographs of the finished surfaces at the depth of cut of $2 \mu \mathrm{m}$ for feed rates of (a) $12 \mathrm{~mm} / \mathrm{min}$, (b) $18 \mathrm{~mm} / \mathrm{min}$, (c) $24 \mathrm{~mm} / \mathrm{min}$, (d) $30 \mathrm{~mm} / \mathrm{min}$, and (e) $36 \mathrm{~mm} / \mathrm{min}$

magnitude of specific energy can also produce high surface temperatures, which sometimes may lead to surface damage [38]. This is particularly critical to dental restorations where the surrounding tooth tissues are very sensitive and vulnerable to high temperatures in intraoral environments with limits to coolant access.

To simplify the model of material resurfacing, the physics of the single diamond girt penetrating into the surface of the material and scratching or abrasion is highly considered. As penetration occurs into a brittle material, elastic displacement is followed by plastic flow and fracture. A central factor in determining the finishing mode (ductile regime versus brittle) is the grit depth of penetration or cut. Brittle materials can be removed in a ductile mode when the grit depths of cut are below a critical grit depth of cut, $d_{\mathrm{c}}$, which is associated with the material properties as follows [39]:

$d_{\mathrm{c}}=0.15\left(\frac{E}{H}\right)\left(\frac{K_{\mathrm{c}}}{H}\right)^{2}$

where $E$ is the Young's modulus, $H$ is the hardness, and $K_{\mathrm{c}}$ is the fracture toughness. According to Eq. (2), the critical grit depth of cut for this porcelain is calculated to be $0.24 \mu \mathrm{m}$.

In abrasive removal, the grit depth of cut is defined as the maximum undeformed chip thickness, which can be calculated as [29]:

$h_{\max }=\left(\frac{3}{C \tan \theta}\right)^{1 / 2}\left(\frac{v_{\mathrm{w}}}{v_{\mathrm{s}}}\right)^{1 / 2}\left(\frac{a}{d_{\mathrm{s}}}\right)^{1 / 4}$ 
(a)

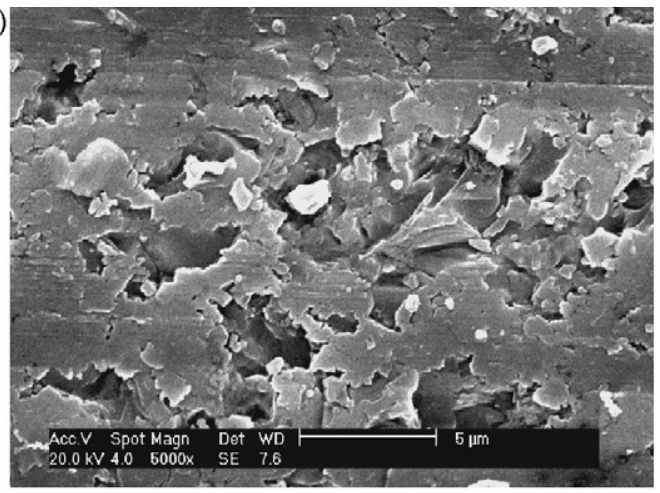

(c)

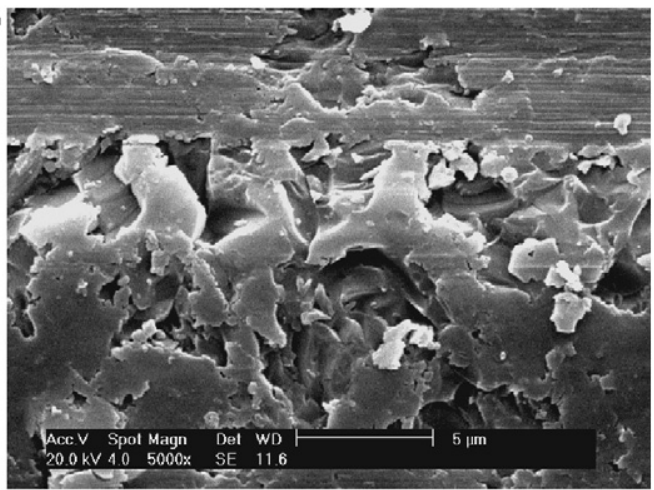

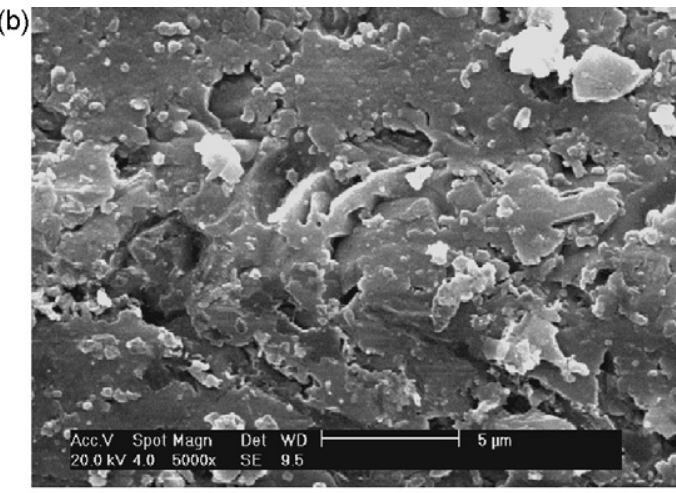

(d)

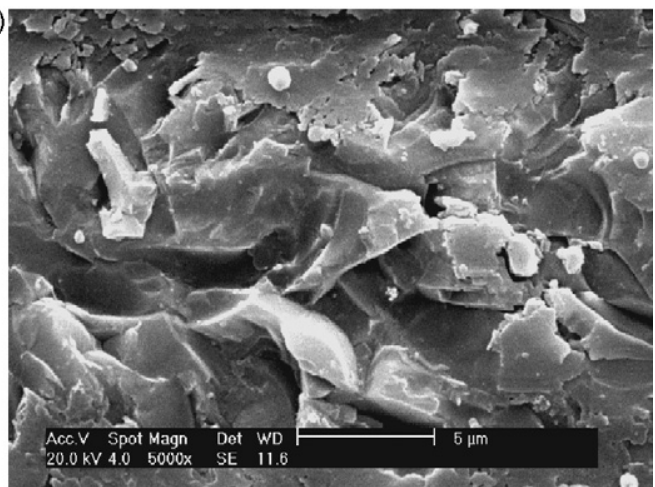

(e)

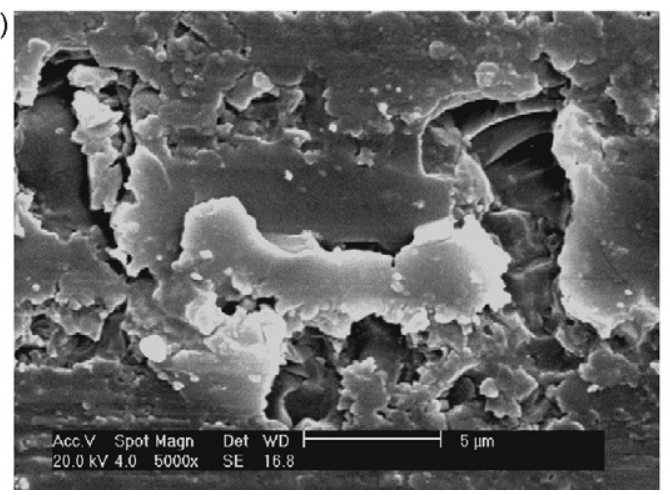

Fig. 9. SEM micrographs of the finished surfaces at the depth of cut of $20 \mu \mathrm{m}$ for feed rates of (a) $12 \mathrm{~mm} / \mathrm{min}$, (b) $18 \mathrm{~mm} / \mathrm{min}$, (c) $24 \mathrm{~mm} / \mathrm{min}$, (d) $30 \mathrm{~mm} / \mathrm{min}$, and (e) $36 \mathrm{~mm} / \mathrm{min}$.

where $C$ is the number of active cutting points per unit area, $\theta$ is the semi-included angle for the undeformed chip, which is taken as $60^{\circ}$ [29], $v_{\mathrm{W}}$ is the bur feed rate, $v_{\mathrm{S}}$ is the bur peripheral speed, $a$ is the depth of cut, and $d_{\mathrm{s}}$ is the bur diameter. In material removal, better surface roughness results from smaller grit depths of cut [29]. According to Eq. (3), the grit depth of cut is related to the fourth root of the depth of cut and to the square root of the feed rate. Therefore, surface roughness is more influenced by the depth of cut than by the feed rate. This explains why in the current study the influence of the depth of cut on surface roughness was significant, while the effect of the feed rate on roughness was insignificant, as shown in Fig. 7.

In removal of most polycrystalline ceramics, microfracture occurs via intergranular or transgranular fracture, or grain dislodgement [30]. In the current study, it is very difficult to observe the grain dislodgement and transgranular fracture because the grain boundaries of the feldspar grains were not easily visible due to their fusion with glass matrix. Plastic flow in finishing of ceramics is similar with the machined plastic metal materials, and it looks smooth [30].

For the diamond bur applied in the current study, the diamond grits per unit area are estimated to be 2500 grits $/ \mathrm{mm}^{2}$ based on the SEM observations of the bur topography in Fig. 10. Given that the fraction of active grits involving removal is generally to be $1-10 \%$ [40], we assumed that the fraction of active grits for the fine bur is $5 \%$. Therefore, $C$ is approximately 125 grits $/ \mathrm{mm}^{2}$. According to Eq. (3), the grit depths of cut are estimated to be $0.068-0.22 \mu \mathrm{m}$, which were smaller than the critical grit penetration depth of $0.24 \mu \mathrm{m}$. 


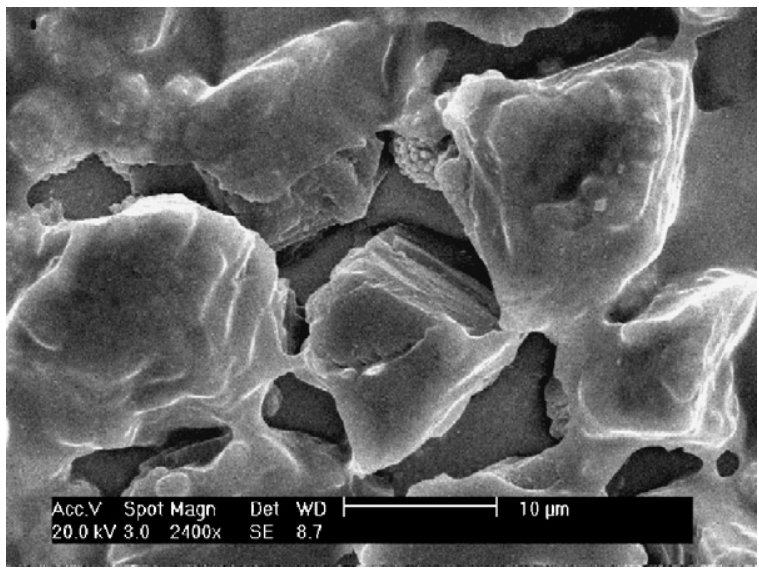

Fig. 10. SEM topography of the used fine diamond bur.

This suggests that the material finishing of the porcelain was dominated by the ductile mode. However, it should be noted that both Eqs. (2) and (3) were based on many assumptions. For example, Eq. (2) assumes that the materials are isotropic and it therefore applies better to glasses than ceramics with grain boundaries [41]. Eq. (3) assumed a simple chip geometry [29]. Furthermore, the diamond grits can function as both sharp and blunt indenters in finishing. Upon contact, a sharp indenter induces very high stress, which remains approximately constant regardless of depth. A rounded indenter induces low stresses on initial contact, which increases with increasing penetration depth [42]. The occurrence of the microfractures in porcelain might be attributed to high pressure-induced stresses beneath the finished surfaces. Furthermore, certain planes in the feldspar crystals in porcelain have lower cleavage stresses than others. Thus, finishing near the fracture threshold can result in some areas that have a ductile response and some that have a component of brittle response. This explains why a certain degree of microfracture was observed on the porcelain surfaces finished in the ductile region using the fine grit diamond bur, as shown in Figs. 8 and 9.

\section{Conclusions}

We investigated the fundamental features in micro-fine finishing of a feldspar porcelain for a typical range of dental operational parameters. Higher feed rate and depth of cut resulted in a more efficient finishing since the energy expended was less. However, higher feed rate and depth of cut likely result in more surface and subsurface damage. Better surface finish and morphology were obtained at low depths of cut or feed rate, resulting in low finishing forces and high specific finishing energies. The high specific finishing energies may cause thermal damage in the surrounding tooth tissues, which can be a problem when the finishing is conducted intraorally. Caution should be taken in micro-fine finishing using fine grit diamond burs to avoid intense finishing- induced heat. The micro-fine finishing mechanism for the feldspar porcelain was dominated by the ductile material removal mode, but a small degree of microfracture occurred. The finishing-induced microcracks on the surfaces are likely to propagate at high loads or stress concentrations. This suggests that the lifetime of porcelain prostheses can be improved by removing the microfractured layer with final polishing.

\section{Acknowledgments}

This work was supported by NSFC Project Grant No. 50475115. We thank Dr. Ulf Griesmann of NIST and Dr. Anthony Flynn of ANU for valuable comments.

\section{Conflict of interest}

The authors have not entered into a commercial relationship with any other individuals or organizations, that might include employment, consultancies, stock ownership, honoraria, paid expert testimony, patent applications/registrations, and grants or other funding, other than that funding by the National Natural Science Foundation of China Project Grant No. 50475115.

\section{References}

[1] Kelly JR. Ceramics in restorative and prosthetic dentistry. Annu Rev Mater Sci 1997;27:443-68.

[2] Thompson VP, Rekow DE. Dental ceramics and the molar crown testing ground. J Appl Oral Sci 2004;12(sp.):26-36.

[3] van Noort R. Dental ceramics. In: van Noort R, editor. Introduction to dental materials. 2nd ed. Oxford: Elsevier; 2002. p. 231-46.

[4] Reiss B, Walther W. Clinical long-term results and 10-year Kaplan-Meier analysis of CEREC restorations. Int $\mathbf{J}$ Comput Dent 2000;3:9-23.

[5] Bindl A, Mormann WH. An up to 5-year clinical evaluation of posterior in-ceram CAD/CAM core crowns. Int J Prosthodont 2002;15:451-6.

[6] Otto T, De Nisco S. Computer-aided direct ceramic restorations: a 10year prospective clinical study of Cerec CAD/CAM inlays and onlays. Int J Prosthodont 2002;15:122-8.

[7] Kelly JR. Clinically relevant approach to failure testing of all-ceramic restorations. J Prosthet Dent 1999;81:652-61.

[8] Thompson Rekow D. Engineering long-term clinical success of advanced ceramic prostheses. J Mater Sci Mater Med 2007;18:47-56.

[9] Tinschert J, Zwez D, Marx R, Anusavice KJ. Structural reliability of alumina-, feldspar-, leucite-, mica- and zirconia-based ceramics. J Dent 2000;28:529-35.

[10] Harvery CK, Kelly JR. Contact damage as failure mode during in vitro testing. J Prosthodont 1996;5:95-100.

[11] Lawn BR, Deng Y, Miranda P, Pajares A, Chai H, Kim DK. Overview: damage in brittle layer structures from concentrated loads. J Mater Res 2002;17:3019-36.

[12] Lawn BR, Deng Y, Lloyd IK, Janal MN, Rekow ED, Thompson VP. Materials design of ceramic-based layer structures for crowns. J Dent Res 2002;81:433-8.

[13] Sindel J, Petschelt A, Grellner F, Dierken C, Greil P. Evaluation of subsurface damage in CAD/CAM machined dental ceramics. J Mater Sci Mater Med 1998;9:291-5. 
[14] Grellner F, Hoscheler S, Greil P, Sindel J, Petschelt A. Residual stress measurements of computer aided design/computer aided manufacturing (CAD/CAM) machined dental ceramics. J Mater Sci 1997;32:6235-42.

[15] Yin L, Jahanmir S, Ives LK. Abrasive machining of porcelain and zirconia with a dental handpiece. Wear 2003;255:975-89.

[16] Song, XF, Yin L, Han YG, Li J. Finite element analysis of subsurface damage of ceramic prosthesis in simulated intraoral dental resurfacing. J Biomed Mater Res Part B Appl Biomater, in press.

[17] Yin L, Song XF, Qu SF, Han YG, Wang H. Surface integrity and removal mechanism in simulated dental finishing of a feldspathic porcelain. $\mathbf{J}$ Biomed Mater Res Part B Appl Biomater 2006;79B:365-78.

[18] Giordano RA, Campbell S, Pober R. Flexural strength of feldspathic porcelain treated with ion exchange, overglaze, and polishing. J Prosthet Dent 1994;71:468-72.

[19] Kelly JR, Giordano R, Pober R, Cima MJ. Fracture surface analysis of dental ceramics: clinically failed restorations. Int J Prosthodont 1990;3:430-40.

[20] Anusavice KJ. Degradability of dental ceramics. Adv Dent Res 1992;6:82-9.

[21] Giordano R. Materials for chairside CAD/CAM-produced restorations. J Am Dent Assoc 2006;137:14S-21S.

[22] Siegel SC, von Fraunhofer JA. Dental cutting: the historical development of diamond burs. J Am Dent Assoc 1998;129:740-5.

[23] Siegel SC, von Fraunhofer JA. Cutting efficiency of three diamond bur grit sizes. J Am Dent Asso 2000;131:1706-10.

[24] Yin L, Ives LK, Jahanmir S, Rekow ED, Romberg E. Abrasive machining of glass-infiltrated alumina with diamond burs. Mach Sci Technol 2001;5:43-61.

[25] Dong X, Yin L, Jahanmir S, Ives LK, Rekow ED. Abrasive machining of glass-ceramics with a dental handpiece. Mach Sci Technol 2000;4:209-33.

[26] Yin L, Song XF, Qu SF, Huang T, Mei JP, Yang ZY, et al. Performance evaluation of a dental handpiece in simulation of clinical finishing using a novel 2-DOF in vitro apparatus. Proc IME H J Eng Med 2006;220:929-38.

[27] Peterson IM, Pajares A, Lawn BR, Thompson VP, Rekow ED. Mechanical characterization of dental ceramics by Hertzian contacts. J Dent Res 1998;77:589-602.
[28] Deng Y, Lawn BR, Lloyd IK. Characterization of damage modes in dental ceramic bilayer structures. J Biomed Mater Res Part B Appl Biomater 2002;63:137-45.

[29] Malkin S. Grinding technology: theory and applications of machining with abrasives. New York: Wiley; 1989.

[30] Jahanmir S, Xu HHK, Ives LK. Mechanisms of material removal in abrasive machining of ceramics. In: Jahanmir S, Ramulu M, Koshy $\mathrm{P}$, editors. Machining of ceramics and composites. New York: Marcel Dekker; 1998. p. 11-84.

[31] Shih AJ, McSpadden SB, Morris TO, Grant MB, Yonushonis TM. High speed and high material removal rate grinding of ceramics using the vitreous bond CBN wheel. Mach Sci Technol 2000;4:43-58.

[32] Westland IAN. The energy requirement of the dental cutting process. J Oral Rehabil 1980;7:51-63.

[33] Hwang TW, Malkin S. Upper bound analysis for specific energy in grinding of ceramics. Wear 1999;231:161-71.

[34] Hwang TW, Malkin S. Grinding mechanisms and energy balance for ceramics. J Manuf Sci Eng 1999;121:623-31.

[35] Hwang TW, Evans CJ, Malkin S. Size effect for specific energy in grinding of silicon nitride. Wear 1999;225-229:862-7.

[36] Zhang LC, Suto T, Noguchi H, Waida T. A study of creep-feed grinding of metallic and ceramic materials. J Mater Process Technol 1995;48:267-74.

[37] Malkin S, Hwang TW. Grinding mechanisms for ceramics. Ann CIRP 1996;45:569-80.

[38] Shaw MC. Principles of abrasive processing. Oxford: Oxford University Press; 1996. p. 213.

[39] Bifano TG, Dow TA, Scattergood RO. Ductile-regime grinding: a new technology for machining brittle materials. ASME J Eng Ind 1991;113:184-9.

[40] Stephenson DJ, Vesalovac D, Manley S, Corbett J. Ultra-precision grinding of hard steels. Precis Eng 2001;25:336-45.

[41] Blaedel KL, Taylor JS, Evans CJ. Ductile-regime grinding of brittle materials. In: Jahanmir S, Ramulu M, Koshy P, editors. Machining of ceramics and composites. New York: Marcel Dekker; 1998. p. 139_ 76.

[42] Morris JC, Callahan DL, Kulik J, Patten JA, Scattergood RO. Origins of the ductile regime in single-point diamond turning of semiconductors. J Am Ceram Soc 1995;78:2015-20. 